Chapman University

Chapman University Digital Commons

Pharmacy Faculty Articles and Research

School of Pharmacy

9-2005

\title{
A Mechanism for the Formation of Nanostructured NiZn Ferrites via a Microemulsion-Assisted Precipitation Method
}

Vuk Uskoković

Chapman University, uskokovi@chapman.edu

Miha Drofenik

Jožef Štefan Institute

Follow this and additional works at: http://digitalcommons.chapman.edu/pharmacy_articles

Part of the Other Chemistry Commons, and the Physical Chemistry Commons

\section{Recommended Citation}

Uskoković V, Drofenik M. A mechanism for the formation of nanostructured NiZn ferrites via a microemulsion-assisted precipitation method. Colloids Surf A Physicochem Eng Asp. 2005;266(1-3):168-174. doi: 10.1016/j.colsurfa.2005.06.022

This Article is brought to you for free and open access by the School of Pharmacy at Chapman University Digital Commons. It has been accepted for inclusion in Pharmacy Faculty Articles and Research by an authorized administrator of Chapman University Digital Commons. For more information,

please contact laughtin@chapman.edu. 


\section{A Mechanism for the Formation of Nanostructured NiZn Ferrites via a Microemulsion-Assisted Precipitation Method}

\section{Comments}

NOTICE: this is the author's version of a work that was accepted for publication in Colloids and Surfaces A: Physicochemical and Engineering Aspects. Changes resulting from the publishing process, such as peer review, editing, corrections, structural formatting, and other quality control mechanisms may not be reflected in this document. Changes may have been made to this work since it was submitted for publication. A definitive version was subsequently published in Colloids and Surfaces A: Physicochemical and Engineering Aspects, volume 266, issue 1-3, in 2005. DOI: 10.1016/j.colsurfa.2005.06.022

The Creative Commons license below applies only to this version of the article.

\section{Creative Commons License}

\section{(C) $(\oplus \Theta$}

This work is licensed under a Creative Commons Attribution-Noncommercial-No Derivative Works 4.0 License.

\section{Copyright}

Elsevier 


\title{
A Mechanism for the Formation of Nanostructured NiZn Ferrites via a Microemulsion-Assisted Precipitation Method
}

\author{
Vuk Uskoković*, Miha Drofenik ${ }^{*, * *}$ \\ * Jožef Stefan Institute, Jamova 39, 1000 Ljubljana, Slovenia \\ ${ }^{* *}$ Faculty of Chemistry and Chemical Engineering, Smetanova 17, 2000 Maribor, Slovenia \\ Corresponding author: Vuk Uskoković, vuk.uskokovic@ijs.si
}

\begin{abstract}
Nanostructured NiZn ferrites were synthesized using two different techniques: first, a precipitation procedure in the reverse micelles of a CTAB/1-hexanol/ $\mathrm{H}_{2} \mathrm{O}$ microemulsion, and second, precipitation in a bulk aqueous solution. XRD measurements, magnetic measurements, TEM imaging, analytical measurements and thermal analyses were used in an attempt to reveal the chemical pathway that leads to the formation of NiZn ferrite in the microemulsion and in the bulk aqueous solution. It was found that reverse micelles do not act as inert nano-sized reactors that influence only morphological properties of the synthesized powders, but have a decisive influence on the identity of the final product when compared to the non-microemulsion procedure, and therefore present the molecular structures which are actively engaged in the chemical pathway according to which the herein presented room-temperature synthesis of NiZnferrite nanoparticles takes place. The influence of the initial $\mathrm{pH}$ on the chemical pathway of reverse-micellar synthesis and the morphology of the synthesized particles was discussed after initially it was found that the $\mathrm{pH}$ of the precipitation ought to be higher than 8 in order to obtain the desired ferrite as a final product.
\end{abstract}

\section{Introduction}

The reverse-micelles synthesis of materials has recently been attracting much attention, mostly because nanostructured materials with designable particle sizes and uniformly de-agglomerated particle morphologies can be relatively easily prepared using such a technique [1]. In addition to research focused on the synthesis of various nanomaterials within reverse-micellar microemulsions, many studies have looked at modeling and/or theoretically predicting the kinetics of the chemical reactions that occur in reverse-micellar domains [2].

In this study we have compared the synthesis of nanostructured NiZn ferrites produced in reverse-micellar microemulsions with a similar chemical procedure performed in bulk conditions. The crystallization pathways from the supersaturated solutions are generally influenced by a number of factors [3], including foreign surfaces, surface-active agents, the $\mathrm{pH}$, and the level of supersaturation. Also, when synthesizing iron compounds using a wet low-temperature method, the identities of the end products are largely affected by the oxidation rate, the $\mathrm{pH}$ and the structure and composition of the initial and intermediate iron species. Considering these effects, it is quite natural to expect that the pathway that leads to the formation of spinel ferrites as part of the 
precipitation procedure would normally be different when performed in a reversemicellar microemulsion than in ordinary bulk solutions.

\section{Experimental}

The following chemicals were used in the procedure: $\mathrm{FeSO}_{4} \cdot 7 \mathrm{H}_{2} \mathrm{O}(>99 \%$, Alfa Aesar), $\mathrm{NiSO}_{4} \cdot 7 \mathrm{H}_{2} \mathrm{O}$ (99.7\%, Podnart), $\mathrm{ZnSO}_{4} \cdot 7 \mathrm{H}_{2} \mathrm{O}(>99 \%$, Alfa Aesar) as precursor salts; CTAB (>99\%, Alfa Aesar) as the surfactant; 1-hexanol (>98\%, Merck-Schuchardt) as the oil phase; de-ionized water as the aqueous phase; $\left(\mathrm{CH}_{3}\right)_{4} \mathrm{NOH}(25 \mathrm{wt} \%, 99.5 \%$ purity, Alfa Aesar) as the precipitating agent; $\mathrm{H}_{2} \mathrm{O}_{2}$ (30 wt \%, Carlo Erba) as the oxidizing agent; $\mathrm{H}_{2} \mathrm{SO}_{4}(99.8 \%$, Carlo Erba) as the acidifying agent; and ethanol (99.8 $\%$, Carlo Erba) and de-ionized water as the washing substances. A multi-microemulsion approach was followed. The first reverse-micellar microemulsion in every synthesizing procedure comprised an acidified (to $\mathrm{pH}=1.6-1.8$ by 1- $\mathrm{M}_{2} \mathrm{SO}_{4}$ in order to prevent oxidation of the $\mathrm{Fe}^{2+}$ species and subsequent precipitation of the yellow-gray $\mathrm{FeOHSO}_{4}$, which at room temperature and at the concentration used in these experiments occurs at $\mathrm{pH} \geq 1.8) 0.237-\mathrm{M}$ aqueous solution of precursor cations $\left(\mathrm{Fe}^{2+}, \mathrm{Ni}^{+}, \mathrm{Zn}^{2+}\right)$, whereas the second microemulsion, which had the same composition as the first, used a 0.5-M aqueous solution of $\left(\mathrm{CH}_{3}\right)_{4} \mathrm{NOH}$ as the alkali precipitating agent. The two microemulsions with the same weight composition of CTAB : 1-hexanol : $\mathrm{H}_{2} \mathrm{O}=30: 55$ : 15 were mixed and aged for 1 hour (if not denoted for longer times later in the paper) at room temperature. The segregation of phases was not observed, so the agglomeration of the particles occurred during their removal from the parent microemulsion. The colloidal precipitate was sedimented by centrifuging ( $3 \mathrm{~min}, 3500 \mathrm{rpm}$ ) and repeated washing with ethanol and de-ionized water. The powder was then dried in air at $60^{\circ} \mathrm{C}$, and subsequently characterized. Measurements of $\mathrm{pH}$ values during the aging times of the mixed precursor and precipitating microemulsions were performed by using a Metrohm $691 \mathrm{pH}$-meter, with the apparatus-indicated values referring not to $\mathrm{pH}$ of the aqueous phase (the close medium of the induced chemical recombinations), but to resulting $\mathrm{pH}$ of an overall microemulsion system. The produced nanoparticles were investigated using transmission electron microscopy (JEOL JEM-2000FX), X-ray diffraction analyses (D4 Endeavour), specific magnetization measurements (MANICS DSM10). The stoichiometry of the synthesized powders was determined using atomic spectroscopy measurements. The Debye-Scherrer equation was used to evaluate the average particle sizes of the synthesized particles.

\section{Results and discussion}

The influence of the reverse micelles on the identity of the final product

The XRD patterns of two different powders synthesized at the same precipitating $\mathrm{pH}=12$, one in bulk conditions, and the other within the reverse-micellar composition range of the $\mathrm{CTAB} / 1$-hexanol $/ \mathrm{H}_{2} \mathrm{O}$ microemulsion, are shown in Fig. 1. In the latter case, a spinel phase that corresponds to the NiZn-ferrite crystal structure was detected; in the former case, hexagonal $\delta$-FeOOH was obtained. There were no significant differences in the XRD patterns and the $\mathrm{M}_{\mathrm{s}}$ in the $\mathrm{H}_{2} \mathrm{O}_{2}$-oxidized and $\mathrm{H}_{2} \mathrm{O}_{2}$-non-oxidized samples. The 
specific saturation magnetization of the spinel sample was $\mathrm{M}_{\mathrm{s}}=5 \mathrm{emu} / \mathrm{g}$, whereas the $\delta$ FeOOH sample had $\mathrm{M}_{\mathrm{s}}=4 \mathrm{emu} / \mathrm{g}$, which is consistent with small average particle sizes, estimated at $3 \mathrm{~nm}$ for the spinel sample and at $5.5 \mathrm{~nm}$ for the $\mathrm{FeOOH}$ sample. It is known that $\delta$-FeOOH is the only $\mathrm{FeOOH}$ modification that exhibits a significant magnetization at room temperature [4]. The estimated size of the synthesized particles matches the estimated size of the reverse micelles' "water pools" (2.5 nm in diameter) for the given water volume of the same microemulsion system [5], which might suggest that the reverse micelles indeed acted like encapsulating nano-reactors, limiting the size of the crystallized particles to the sizes of their own pools. This view of the role of reverse micelles in the formation of synthesized material is in agreement with much of the current thinking in this area, although the dynamic interactions among reverse micelles has recently been pointed out as the major influencing factor $[2,6]$.

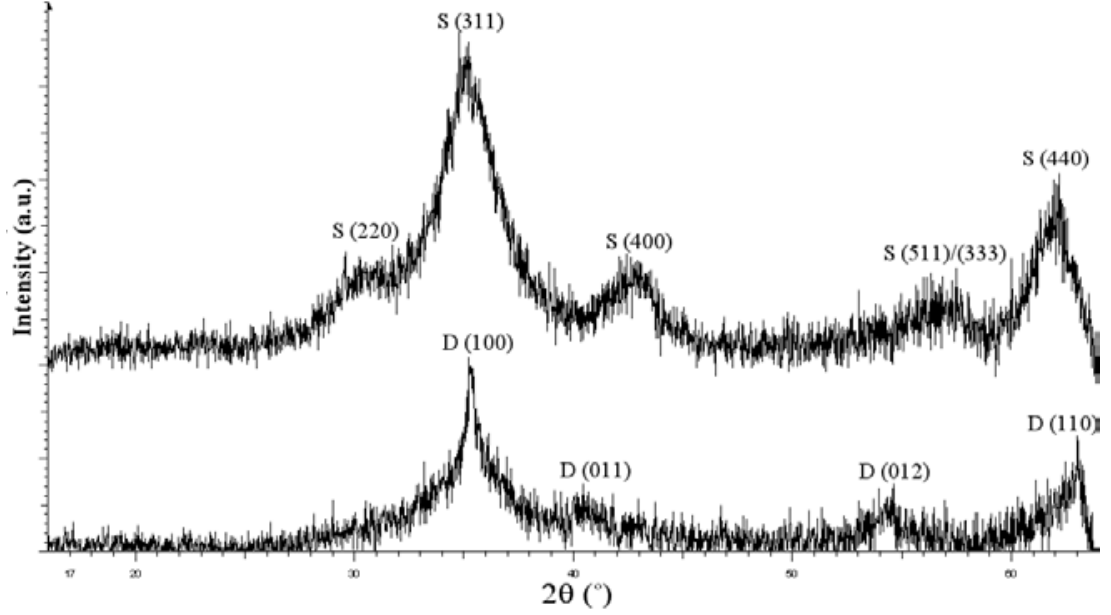

Fig.1. X-ray diffractograms of the powders synthesized by the same precipitation procedure at precipitating $\mathrm{pH}=12$, with (upper) and without (lower) reverse-micellar microemulsion. The peaks denoted with an $\mathrm{S}$ are spinel-derived, whereas the peaks denoted with a $\mathrm{D}$ are $\delta$-FeOOH-derived.

The same synthesizing procedures were performed in bulk aqueous solutions in the presence of $3 \mathrm{wt} \% \mathrm{CTAB}$, and there were no significant differences in the XRD patterns when compared to the sample synthesized without the presence of CTAB. Therefore, it is not the CTAB that influences the formation of spinel ferrite, rather it is the reverse-micellar structure of the microemulsion.

The influence of $\mathrm{pH}$ on the identity and the properties of the microemulsion-assisted synthesized samples

If the precipitating $\mathrm{pH}$ in the process of reverse-micellar synthesis exceeded 8 , the spinel product was obtained, whereas when the $\mathrm{pH}$ was below $8, \alpha-\mathrm{FeOOH}$ was formed as the major product (Fig.2). The specific saturation magnetization $\left(\mathrm{M}_{\mathrm{s}}\right)$ values of the samples synthesized in the $\mathrm{pH}$ range of 8-10 had much lower values of about $1 \mathrm{emu} / \mathrm{g}$, compared to the samples synthesized at pHs of 10-13.5, which had $\mathrm{M}_{\mathrm{s}}=4-5.5 \mathrm{emu} / \mathrm{g}$. The increase in the $\mathrm{M}_{\mathrm{s}}$ values with the increase in the $\mathrm{pH}$ of the precipitation is consistent with a similar increase in the samples' crystallinity, which was observed in a previous study [7]. 


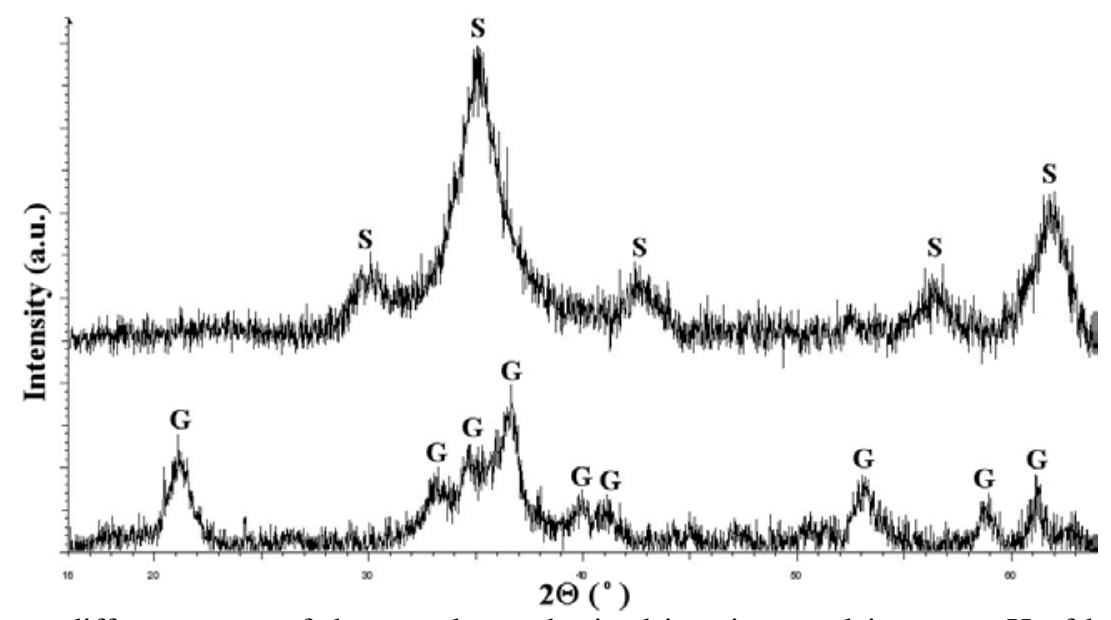

Fig.2. X-ray diffractograms of the sample synthesized in microemulsion at a $\mathrm{pH}$ of below 8 (lower) and above 8 (upper). The spinel-derived peaks are denoted with an $\mathrm{S}$, while the goethite-derived peaks are denoted with a G.

The analytically determined stoichiometry of the samples synthesized at a precipitating $\mathrm{pH}=9.7$ and 12 were $\mathrm{Ni}_{0.49} \mathrm{Zn}_{0.68} \mathrm{Fe}_{1.83} \mathrm{O}_{4}$ and $\mathrm{Ni}_{0.48} \mathrm{Zn}_{0.73} \mathrm{Fe}_{1.79} \mathrm{O}_{4}$, respectively, which suggests that apart from the XRD-determined structure, there were no significant differences in the elemental composition of the samples synthesized at medium and higher precipitating $\mathrm{pH}$ values, in spite of the differences in the morphologies. The measured concentration of cations was also the same in both samples, which is another indication that their chemical composition was approximately the same.

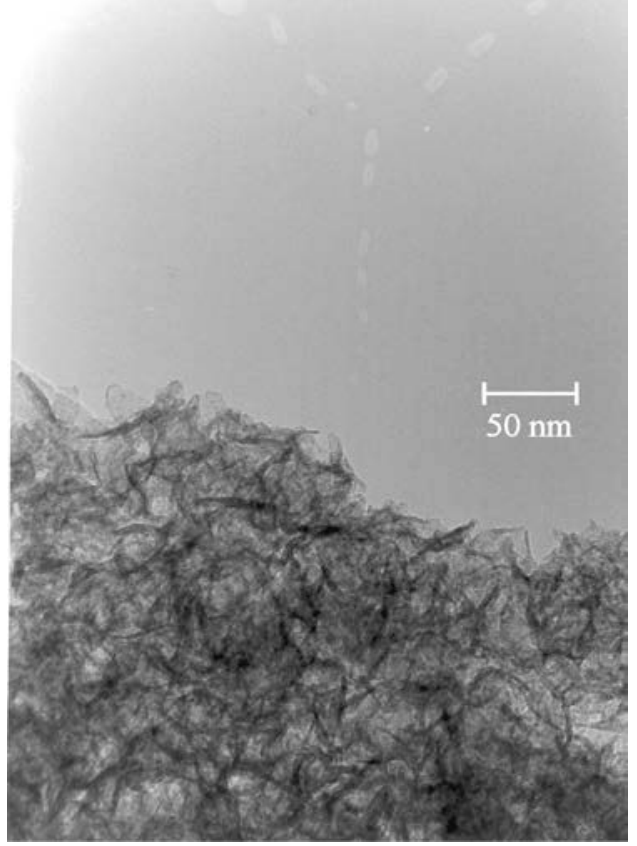

a.)

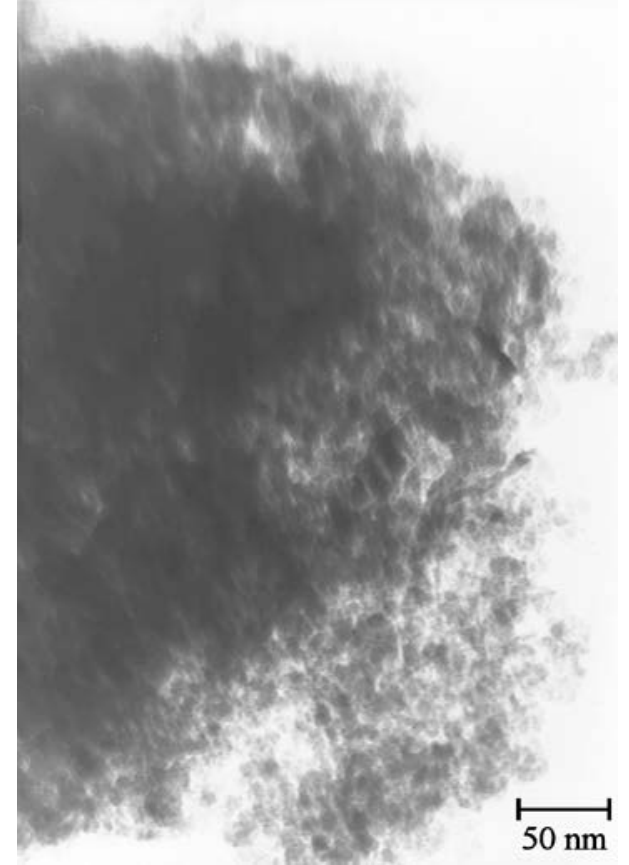

b.)

Fig 3. TEM images of the samples synthesized in microemulsion at the precipitating $\mathrm{pH}=9$ (a) and $\mathrm{pH}=$ 11 (b).

TEM images of the samples synthesized at the precipitating $\mathrm{pH}=9$ and $\mathrm{pH}=11$ are shown in Fig. 3. Fig 3a shows agglomerates of nanosized acicular particles, whereas 
agglomerates of rather spherical particles with sizes of a few nanometers are seen in Fig. 3b. Acicular particles were present to varying degrees in all the samples synthesized at medium $\mathrm{pH}$ values (8-11), whereas the samples synthesized at $\mathrm{pH} \geq 12$ consisted of spherical particles only. We suggest that there are four possible explanations for the existence of acicular particles in the spinel samples:

I) Different modifications of $\mathrm{FeOOH}$ are known to represent intermediate compounds during the formation of many spinel-type ferric compounds [8]. A pH $<12$ might always induce the formation of acicular $\alpha-\mathrm{FeOOH}$, which might be sufficiently crystalline to be detected with XRD. The isoelectric point, which influences the extent of the aggregation of the growing particles, was found to be around $\mathrm{pH}=9$. Since a mineral such as $\mathrm{FeOOH}$ is regarded as an infinite n-mer extension of $\left[\mathrm{Fe}_{2}(\mathrm{OH})_{2}\right]^{4+}[3]$, the negligible repulsion between the growing particles at around $\mathrm{pH}=9$ might be the reason for the formation of acicular particles.

II) It is well known that the rate of transformation of solid phases increases with increasing $\mathrm{pH}[9,10]$. The higher $\mathrm{pH}$ usually leads to a higher rate of nucleation, and therefore to a larger number of particles of smaller sizes [11], which might be another reason for the difference in the morphology of the particles synthesized at different values of $\mathrm{pH}$.

III) The third possibility is that the increased $\mathrm{OH}^{-}$concentration might substantially eliminate the anions $\left(\mathrm{SO}_{4}{ }^{2-}, \mathrm{Br}^{-}\right)$that might otherwise promote the uniaxial growth of particles by adsorption at specific sites of the growing $\alpha-\mathrm{FeOOH}$ particles, or by chemically combining with the particles leading to their specific agglomeration [8]. Sulfate ions, which may promote the appearance of $\alpha$-phases [9], are only one of the many ionic species known to form complexes with the extremely hydrolyzable ferric ion. During the synthesis of MnZn ferrite using the same chemical procedure, acicular particles were not produced [12], which suggests that $\mathrm{Ni}^{2+}$ must be involved in the mechanism of the uniaxial growth of the particles.

IV) The fourth possibility is that the lower $\mathrm{pH}$ values under given experimental conditions favor the formation of elliptical or very long, rod-shaped reverse micelles, which are known to exist in microemulsion systems that comprise CTAB as the surfactant [13,14,15]. It is also known that an alkali substance [16], salts [13] or cosurfactant [17,18], such as 1-hexanol [19], might induce a spherical-to-worm-like transition. Elliptical and spherical CTAB micelles are known to be able to co-exist [20], which might explain why the samples synthesized at medium $\mathrm{pH}$ values $(\mathrm{pH}=10-11)$ comprised not just acicular, but spherical particles as well.

\section{The proposed chemical pathway and the effects of compartmentalizing the reactants}

A simplified chemical pathway that leads to the formation of NiZn ferrite from the starting process of the precipitation of divalent precursor cations might be summarized as follows:

$$
\begin{aligned}
& \mathrm{Fe}^{2+}+1 / 4 \mathrm{O}_{2}+\mathrm{H}^{+} \rightarrow \mathrm{Fe}^{3+}+1 / 2 \mathrm{H}_{2} \mathrm{O} \\
& \mathrm{Fe}^{2+}+2 \mathrm{OH}^{-} \rightarrow \mathrm{Fe}(\mathrm{OH})_{2} \\
& 4 \mathrm{Fe}^{2+}+\mathrm{O}_{2}+6 \mathrm{H}_{2} \mathrm{O} \rightarrow 4 \mathrm{FeOOH}+8 \mathrm{H}^{+}
\end{aligned}
$$




$$
\begin{aligned}
& \mathrm{Ni}^{2+}+\mathrm{Zn}^{2+}+4 \mathrm{OH}^{-} \rightarrow \mathrm{Ni}(\mathrm{OH})_{2}+\mathrm{Zn}(\mathrm{OH})_{2} \\
& \mathrm{Fe}^{3+}+3 \mathrm{H}_{2} \mathrm{O} \rightarrow \mathrm{Fe}(\mathrm{OH})_{3}+3 \mathrm{H}^{+} \\
& 4 \mathrm{Fe}(\mathrm{OH})_{2}+\mathrm{O}_{2} \rightarrow 4 \mathrm{FeOOH}+2 \mathrm{H}_{2} \mathrm{O} \\
& \mathrm{Fe}(\mathrm{II})_{(\mathrm{s})}+1 / 4 \mathrm{O}_{2}+\mathrm{H}_{2} \mathrm{O} \rightarrow \mathrm{Fe}(\mathrm{III})_{(\mathrm{s})}+\mathrm{OH}^{-}+1 / 2 \mathrm{H}_{2} \mathrm{O} \\
& \mathrm{Fe}(\mathrm{OH})_{3} \rightarrow \mathrm{FeOOH}+\mathrm{H}_{2} \mathrm{O} \\
& \text { Only if pH }>8, \\
& 2 \mathrm{Fe}(\mathrm{III})_{(\mathrm{s})}+1 / 2 \mathrm{Ni}(\mathrm{OH})_{2}+1 / 2 \mathrm{Zn}(\mathrm{OH})_{2} \rightarrow \mathrm{Ni}_{0.5} \mathrm{Zn}_{0.5} \mathrm{Fe}_{2} \mathrm{O}_{4}+2 \mathrm{H}_{2} \mathrm{O}
\end{aligned}
$$

When $\mathrm{H}_{2} \mathrm{O}_{2}$ is used as an oxidant, then the following reaction also applies: $\mathrm{Fe}^{2+}+\mathrm{H}_{2} \mathrm{O}_{2} \rightarrow \mathrm{Fe}^{3+}+\mathrm{OH}^{-}+\mathrm{OH}^{\cdot}$

The chemical reactions described by equations 1-4 are actuated immediately after the moment of mixing two microemulsions, whereas the first microemulsion comprises aqueous solution of precursor cations and the other microemulsion carries precipitating agent in the water 'pools' of its reverse micelles. The reactions described by equations 58 describe processes that lead to the completion of oxidation of ferrous ions, and their precipitation within the range of their solubility limits. The initial precipitate should mostly comprise amorphous gel of divalent precursor cations hydroxides. Oxidized ferric ions are then at first incorporated together with unoxidized ferrous ions in the intermediate compound of Green Rust II (which is known to present an intermediate when using sulphate precursor salts [21]). The intermediate precipitate of Green Rust II, later with subsequent oxidation of remaining ferrous ions, transforms in the precipitate of certain form of $\mathrm{FeOOH}$, depending on the $\mathrm{pH}$ value of the solution, as well as on possibly catalyzing effects of certain dissolved ions.

We believe that the reason why the desired ferrite was formed only in the microemulsion, and not in the absence of the microemulsion, is that the compartmentalization of the reactants in small, nanosized droplets of water increases the rate of oxidation of ferrous ions, and thus makes the formation of mixed zinc ferrite likely, even for a relatively short aging time of 1 hour. The reason why $\delta$-FeOOH was only formed in bulk conditions is that the oxidation was probably not as fast as in the microemulsion from the very beginning, but only after the precipitate of $\mathrm{Fe}(\mathrm{OH})_{2}$ was already formed. This statement is based on observing the color changes in both the bulk and the microemulsion conditions. The color of the microemulsion changed from black to orange approximately 5 minutes after the precipitation reaction was initiated, which is a result of the formation of $\mathrm{Fe}^{3+}$ ions. In contrast, the color of the bulk solution remained black throughout the whole aging experiment, and turned orange only if a foreign oxidizing agent such as $\mathrm{H}_{2} \mathrm{O}_{2}$ was added. It has been reported that the rate of oxidation of $\mathrm{Fe}^{2+}$ and the subsequent formation of needle-like FeOOH particles by spontaneous air oxidation was from 100 to 1000 times faster in reverse micelles than in a bulk solution [22]. In the case of certain iron complexes, a 2-10-fold increase in the rate of dissociation was measured in comparison to the pure aqueous solution (cited in [23]). It is possible that the reason for the faster rate of $\mathrm{Fe}^{2+}$ oxidation in reverse micelles compared to the bulk conditions might lie in the atypical structure of water as a solvent in reverse 
micelles. It was suggested that the increase in hydrogen bonding between water molecules in a thin layer neighboring to surfactants may form a field where easy transfer of electrons from $\mathrm{Fe}^{2+}$ to $\mathrm{Fe}^{3+}$ occurs by a tunnelling effect [22], whereby the excess electrons will be consumed in aqueous solution to produce hydroxide ions in the presence of dissolved oxygen. The oxidation of $\mathrm{Fe}^{2+}$ with the decomposition of $\mathrm{H}_{2} \mathrm{O}$ is, by considering thermodynamic data, proven to be an energetically favorable process.

The precipitation reaction should be slower in a reverse-micellar medium, when considering the necessary coupling of the rate constant of the chemical reaction and the rate constant of the fusion of reverse micelles, which must happen prior to the particular reaction [6]. The slower rate of the precipitation when the synthesis is performed within reverse micelles compared to the bulk conditions could be another effect that would, together with the faster rate of oxidation in the former case, lead to better conditions for the formation of ferrite in the microemulsion only, and not in the bulk solution. Oxidation is known to proceed much faster when the oxidized species are diluted than when they are precipitated, which is the reason why decreasing the rate of precipitation by compartmentalizing the reactants increases the rate of oxidation. On the other hand, $\mathrm{Fe}^{2+}$ and $\mathrm{Fe}^{3+}$ yield insoluble hydroxide phases in alkaline solutions, which decreases the redox potential for the oxidation reaction to about $0.52 \mathrm{~V}$, and increases the rate of oxidation of the diluted ferrous ions [24]. In other words, the oxidation of $\mathrm{Fe}^{2+}$ is driven forward by the removal of $\mathrm{Fe}^{3+}$ ions from the solution in form of hydroxide precipitate. Considering redox-potentials, it is obvious that the precipitation of ferric ions increases the rate of oxidation of dilluted ferrous ions. This might explain why the spherical and more magnetic particles were obtained at higher $\mathrm{pH}$ values when oxidation occurred faster due to the faster precipitation and the whole transition of $\mathrm{FeOOH}$ to ferrite happened in a faster way.

The influence of the initial $p H$ on the chemical pathway of reverse-micellar synthesis

A typical $\mathrm{pH}$ vs. aging-time dependence for the final precipitating $\mathrm{pH}=12$ is shown in Fig. 4a. The sudden decrease in the $\mathrm{pH}$ value just as the precipitation is initiated is due to the precipitation of precursor cations and the subsequent decrease of the $\mathrm{OH}^{-}$ concentration (eq. 2, 3,4) in the colloid solution, and the hydrolysis reactions of the oxidation species (eq. 3,5 ).

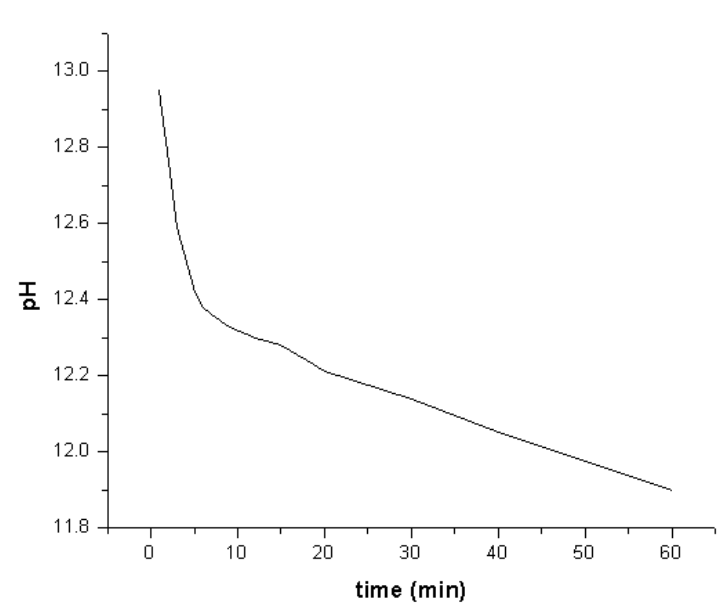

a.)

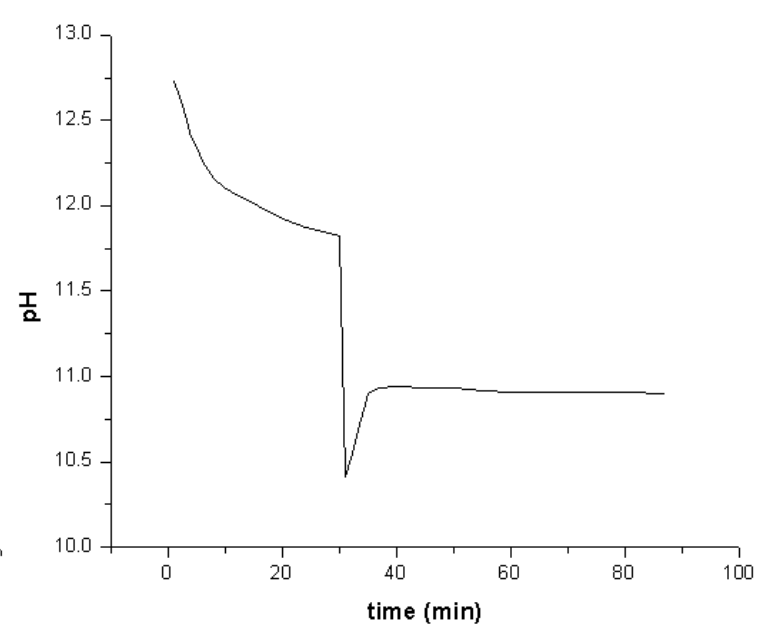

b.) 
Fig. 4. Dependence of $\mathrm{pH}$ value versus aging time for the higher precipitating $\mathrm{pH}$ value case for the $\mathrm{H}_{2} \mathrm{O}_{2}$ non-oxidized (a) and the $\mathrm{H}_{2} \mathrm{O}_{2}$-oxidized microemulsion-assisted synthesized sample (b).

Changes in the initiating $\mathrm{pH}$ of the precipitation bring about two opposite effects: with increasing the initial $\mathrm{pH}$ value, the $\mathrm{OH}^{-}$concentration increases, which favors faster rates of oxidation, but the precipitation proceeds faster too, which leads to longer times needed to complete the $\mathrm{Fe}^{2+}$ oxidation process [9]. With the proposed slowing down of the precipitation reaction due to coupled intermicellar exchange to the rate of the chemical reaction itself, it is possible that the former effect - oxidation - is favored, which consequently favors the faster formation of NiZn ferrite, or its formation at all. The shorter the time needed for Fe ions to precipitate, the faster the oxidation occurs. A sudden decrease in $\mathrm{pH}$ at the moment when the $\mathrm{H}_{2} \mathrm{O}_{2}$ is introduced into the microemulsion (Fig. 4b) is due to its immediate dissociation in an alkali medium:

$$
\mathrm{H}_{2} \mathrm{O}_{2} \rightarrow \mathrm{H}^{+}+\mathrm{HO}_{2}^{-}
$$

The reaction proceeds:

$\mathrm{HO}_{2}^{-}+\mathrm{H}_{2} \mathrm{O}+2 \mathrm{e}^{-} \rightarrow 3 \mathrm{OH}^{-}$ which implies an increase in $\mathrm{pH}$ that follows.

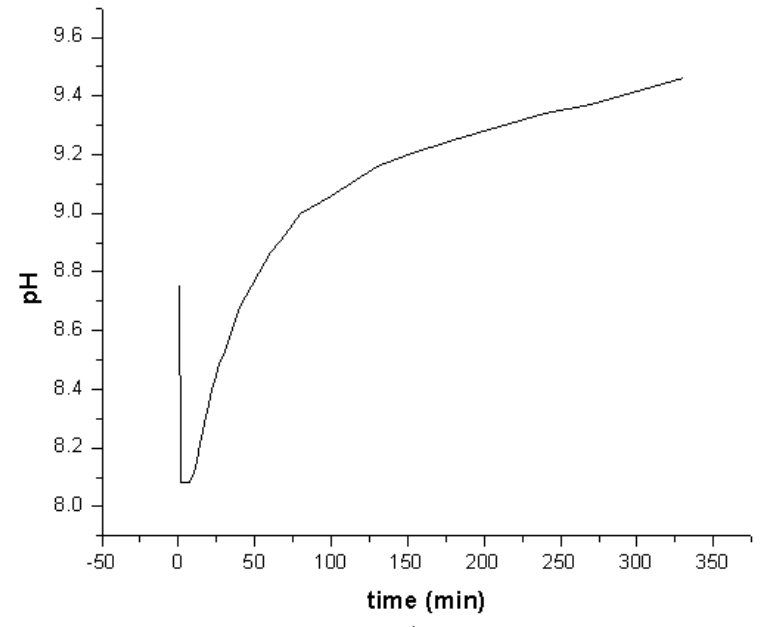

a.)

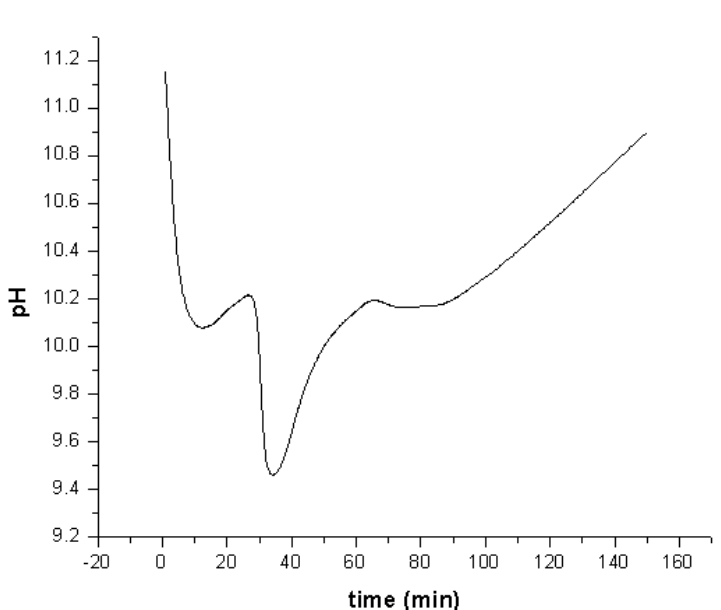

b.)

Fig.5. Dependence of $\mathrm{pH}$ value versus aging time for the lower precipitating $\mathrm{pH}$ value case for the $\mathrm{H}_{2} \mathrm{O}_{2}$ non-oxidized (a) and the $\mathrm{H}_{2} \mathrm{O}_{2}$-oxidized microemulsion-assisted synthesized sample (b).

It was observed that if the $\mathrm{pH}$ values during the process do not fall below $\mathrm{pH}=$ 10 , the $\mathrm{pH}$ value constantly decreases and therefore the equilibrium state is reached with the $\mathrm{pH}$ vs. time curve sloping downwards, as shown in Fig. 4. On the other hand, when the $\mathrm{pH}$ value of the solution falls below approximately 10 (Fig. 5), a range of increasing $\mathrm{pH}$ values would follow a decreasing $\mathrm{pH}$ value range, and equilibrium would be reached with the $\mathrm{pH}$ vs. time curve sloping upwards. The decreasing $\mathrm{pH}$ with aging time is most probably a sign of the oxidation of ferrous species in the solution, i.e., in the aqueous phase of the microemulsion, whereas the increasing trend of the dependence of $\mathrm{pH}$ versus time is a sign of the oxidation of ferrous ions already precipitated in the form of a colloidal precipitate (eq. 7). This suggests that in the cases of higher $\mathrm{pH}$ values shown in Fig. 4, both precipitation and oxidation were favored from the very start of the precipitation reaction, whereas the trend of increasing $\mathrm{pH}$ vs. aging time at medium and lower precipitating $\mathrm{pH}$ values suggests that the precipitation of precursor cations in the 
form of hydroxides was favored over the rate of oxidation, so that after the cations were precipitated, oxidation reactions continued. This difference in the precipitation rate depending on the $\mathrm{pH}$ value is to be expected when considering the fact that the higher $\mathrm{pH}$ within the reverse micelles would lead to a greater repulsion between them and to a consequently slower rate of their merging.

\section{Conclusions}

Different mechanisms for the formation of NiZn ferrite, which was to have the $\mathrm{Ni}_{0.5} \mathrm{Zn}_{0.5} \mathrm{Fe}_{2} \mathrm{O}_{4}$ stoichiometric formula, in bulk solution, as well as in a reverse-micellar $\mathrm{CTAB} / 1$-hexanol/ $/ \mathrm{H}_{2} \mathrm{O}$ microemulsion at lower and higher precipitating $\mathrm{pH}$ values were discussed in terms of the evidence from XRD patterns, different particle morphologies shown in TEM images, different visual appearance throughout the aging time of the precipitate and different changes in $\mathrm{pH}$ of the synthesizing microemulsion versus aging time. When performing the same chemical procedure with and without the reverse micelles, different products were obtained: nanocrystalline NiZn ferrite with an analytically determined stoichiometry of $\mathrm{Ni}_{0.5} \mathrm{Zn}_{0.7} \mathrm{Fe}_{1.8} \mathrm{O}_{3.9}$ in the former case, and $\delta$ $\mathrm{FeOOH}$ in the latter case. Faster rates of oxidation and slower rates of precipitation when the synthesis was performed in reverse micelles rather than in bulk conditions were suggested as the reason for the difference in the chemical identity of the final product for these two chemical procedures. If the $\mathrm{pH}$ of the precipitation decreases below 8 during the aging procedure in the microemulsion, goethite was obtained as the main product. Otherwise, NiZn ferrite with a lower magnetization and acicular particles were obtained in the precipitating $\mathrm{pH}$ range of 8-10, and higher magnetization and spherical particles in the precipitating $\mathrm{pH}$ range of 11-13.5. The formation of acicular particles below a certain range of the precipitating $\mathrm{pH}$ was discussed and related to the presence of the acicular form of $\mathrm{FeOOH}$ as the intermediate phase in the chemical pathway of the formation of NiZn ferrite, and on the oxidation reactions performed over already precipitated ferrous ions in the lower $\mathrm{pH}$ case, whereas the oxidation is thought to be performed over dissolved ferrous ions in the higher $\mathrm{pH}$ value case.

\section{Acknowledgements}

Support by the Ministry of Education, Science and Sports of the Republic of Slovenia within the National research Program is gratefully acknowledged.

\section{References}

1. D. O. Yener, H. Giesche - "Synthesis of Pure and Manganese-, Nickel-, and ZincDoped Ferrite Particles in Water-in-Oil Microemulsions", Journal of the American Ceramic Society 84 (9) 1987-95 (2001).

2. R. Zana, J. Lang - "Dynamics of Microemulsions", in Microemulsions: Structure and Dynamics, edited by S. E. Friberg and P. Bothorel, Boca Raton: CRC Press, 153 - 72 (1987).

3. S. T. Martin - "Properties and Dissolution of Iron and Manganese Oxides", Chapter 4 of Environmental Catalysis, edited by V. H. Grassian (2003). 
4. L. H. Perng, I.-C. Tung, T. S. Chin - "Synthesis and Properties of Nanocrystalline $\delta$-FeOOH”, Journal de Physique IV France 7, C1-519-20 (1997).

5. E. Rodenas, M. Valiente - "The Determination of Some Physical Properties of Reverse CTAB Micelles in 1-Hexanol”, Colloids and Surfaces 62, 289 - 95 (1992).

6. U. Natarajan, K. Handique, A. Mehra, J. R. Bellare, K. C. Khilar - "Ultrafine Metal Particle Formation in Reverse Micellar Systems: Effects of Intermicellar Exchange on the Formation of Particles”, Langmuir 12, 2670 - 78 (1996).

7. V. Uskoković, M. Drofenik - "Synthesis of Nanocrystalline Nickel-Zinc Ferrites via a Microemulsion Route”, Materials Science Forum 453 - 4, 225 - 30 (2004).

8. G. Bate - "Recording Materials", in Ferromagnetic Materials, edited by E. P. Wohlfarth, North-Holland Publishing Company (1980).

9. C. Domingo, R. Rodriguez-Clemente, M. A. Blesa - "The Pathways to Spinel Iron Oxides by Oxidation of Iron (II) in Basic Media”, Materials Research Bulletin 26, 47 - 55 (1991).

10. T. Sugimoto, E. Matijević - "Formation of Uniform Spherical Magnetite Particles by Crystallization from Ferrous Hydroxide Gels”, Journal of Colloid and Interface Science 74 (1), 227 - 43 (1980).

11. G. Wang, G. Whittaker, A. Harrison, L. Song - "Preparation and Mechanism of Formation of Acicular Particles by Decomposition of Ferric and Ferrous Salts in Aqueous Solution Using Microwave Radiation”, Materials Research Bulletin 33 (11), 1571 - 79 (1998).

12. A. Košak, D. Makovec, A. Žnidaršič, M. Drofenik - "Preparation of MnZnFerrite with Microemulsion Technique”, Journal of the European Ceramic Society 24 (6) 959 - 62 (2003).

13. Y. Liu, W. Wang, Y. Zhan, C. Zheng, G. Wang - "A Simple Route to Hydroxyapatite Nanofibers”, Materials Letters 56, 496 - 501 (2002).

14. S. Xu, H. Zhou, J. Xu, Y. Li - "Synthesis of Size-Tunable Silver Iodide Nanowires in Reverse Micelles”, Langmuir 18, 10503 - 4 (2002).

15. M. P. Pileni, A. Hammounda, I. Lisiecki, L. Motte, N. Moumen, J. Tanori "Control of the Size and Shape of Nanoparticles", in Fine Particles Science and Technology, edited by E. Pelizzetti, Kluwer Academic Publishers, 413 - 29 (1996).

16. F. G. Sanchez, C. C. Ruiz - "Intramicellar Energy Transfer in Aqueous CTAB Solutions”, Journal of Luminiscence 69, 179 - 86 (1996).

17. X. Fang, C. Yang - “An Experimental Study on the Relationship between the Physical Properties of CTAB/Hexanol/Water Reverse Micelles and $\mathrm{ZrO}_{2}-\mathrm{Y}_{2} \mathrm{O}_{3}$ Nanoparticles Prepared”, Journal of Colloid and Interface Science 212, 242 - 51 (1999).

18. J. Yang - "Viscoelastic Wormlike Micelles and their Applications”, Current Opinion in Colloid \& Interface Science 7, 276 - 81 (2002).

19. B. Lindman, H. Wennerstrom - "Micelles. Amphiphile Aggregation in A queous Solution” in Topics in Current Chemistry 87: Micelles, Springer-Verlag Berlin Heidelberg (1980). 
20. Z. Lin, J. J. Cai, L. E. Scriven, H. T. Davis - "Spherical-to-Wormlike Micelle Transition in CTAB Solutions”, Journal of Physical Chemistry 98, 5984 - 93 (1994).

21. J. Dufour, J. O. Marron, C. Negro, R. Latorre, A. Formoso, F. Lopez-Mateos "Mechanism and Kinetic Control of the Oxyprecipitation of Sulphuric Liquors from Steel Pickling”, Chemical Engineering Journal 68, 173 - 87 (1997).

22. K. Inouye, R. Endo, Y. Otsuka, K. Miyashiro, K. Kaneko, T. Ishikawa "Oxygenation of Ferrous-Ions in Reversed Micelle and Reversed MicroEmulsion”, Journal of Physical Chemistry 86 (8), 1465 - 69 (1982).

23. J. Sjöblom, R. Lindberg, S. E. Friberg - "Microemulsions - Phase Equilibria Characterization, Structures, Applications and Chemical Reactions”, Advances in Colloid and Interface Science 95, 125 - 287 (1996).

24. I. Filipović, S. Lipanović - "Opća i anorganska kemija”, Školska knjiga, Zagreb (1985).

25. T. Wang, Y. Jin, Z. Wang, Z. Yu - “A Study of the Morphology of the Goethite Crystallization Process”, Chemical Engineering Journal 69, 1-5 (1998).

26. T. Sugimoto, A. Muramatsu - "Formation Mechanism of Monodispersed $\alpha-\mathrm{Fe}_{2} \mathrm{O}_{3}$ Particles in Dilute $\mathrm{FeCl}_{3}$ Solutions”. Journal of Colloid and Interface Science 184, 626 - 38 (1996). 